\title{
Morphological analysis of Yarrowia lipolytica under stress conditions through image processing
}

\author{
F.M. Kawasse, P.F. Amaral, M.H.M. Rocha-Leão, \\ A.L. Amaral, E.C. Ferreira, M.A.Z. Coelho
}

\begin{abstract}
Stress conditions (thermal and oxidative) were applied to Yarrowia lipolytica culture. A rearrangement in cell metabolism as well as dimorphism was observed under these conditions. An image analysis procedure was employed for morphology characterization, and a net increase of around $25 \%$ on hyphae formation was detected. A significant increment in total hyphal length was detected, compared with the control system. The results obtained lead to the consideration of a possible relationship between dimorphism and a cell response mechanism to stress conditions.
\end{abstract}

Keywords Cell morphology, Yeast, Yarrowia lipolytica, Image analysis, Stress

\section{1}

\section{Introduction}

Yarrowia lipolytica is an aerobic micro-organism capable of producing important metabolites and has an intense secretory activity, which justifies efforts to use it in industry (as a biocatalyst), in molecular biology and in genetics studies. Dimorphism refers to the ability of fungi to grow in two distinct forms, usually as single oval cells or as a filament, and to be reversible between each one. The cell shape is controlled by environmental factors, as shown by some authors $[1,2,3]$.

Y. lipolytica has been considered an adequate model for dimorphism studies in yeasts, since it has an efficient system for genetic engineering transformation, and it is easy to distinguish between its morphological forms, in

Received: 28 August 2002 / Accepted: 28 January 2003

Published online: 2 April 2003

(C) Springer-Verlag 2003

F.M. Kawasse, P.F. Amaral, M.H.M. Rocha-Leão, M.A.Z. Coelho ( $\square$ ) Departamento de Engenharia Bioquímica, Escola de Química/UFRJ, Centro de Tecnologia, E-203, Rio de Janeiro, Brazil

E-mail: alice@eq.ufrj.br

Tel.: +55-21-25627622; Fax: +55-21-25627567

A.L. Amaral, E.C. Ferreira, M.A.Z. Coelho

Centro de Engenharia Biológica,

Universidade do Minho, Braga, Portugal

M.A.Z. Coelho

Departamento de Química,

Universidade de Aveiro, Aveiro, Portugal

Financial support and scholarships provided by CNPq, PRONEX and CAPES (Brazil) are grateful acknowledged. A.L. Amaral was supported by PRAXIS XXI/BD/20325/99 grant of Fundação para a Ciência e a Tecnologia (Portugal). contrast to $S$. cerevisiae, which does not produce true filaments and exhibits pseudo-hyphae growth under nitrogen-limited conditions. The yeast-to-mycelium transition is associated with unipolar growth, asymmetric division, large polarly located vacuoles and repression of cell separation after division [4].

$Y$. lipolytica has a hyphae diameter corresponding to $60-100 \%$ of its single cell stage $[5,6]$. The true mycelium consists of septated hyphae 3-5 m wide and several millimeters long. The apical cells frequently exceed $100 \mathrm{~m}$, while the segments measure 50-70 $\mathrm{m} \mathrm{[7].} \mathrm{The} \mathrm{germination}$ exhibits a bipolar pattern, and there is no case of overposition in germination locus [6].

It is believed that yeast dimorphism is related to a defense mechanism to adverse conditions, such as temperature and nutritional changes [8]. In wild strains, such as the one employed in this work, the hyphae growing ability can provide a selective advantage when facing conditions of stress $[9,10]$. It is known that, specifically in $Y$. $l i$ polytica, the carbon source employed has no influence on cell morphology and has a medium $\mathrm{pH}$. However, their morphology is considered to be strongly dependent on the nitrogen source and, if the mitochondrial respiration is inhibited, no hyphae formation is achieved $[7,10]$.

Fungal dimorphism is generally characterized by the presence of many intermediate morphological forms, displaying a broad distribution of cell sizes and shapes. Nevertheless, under certain conditions, one particular morphology may dominate [11]. This wide morphology spectrum greatly affects fermentation performance, since it induces rheological changes and consequently leads to mass and heat transfer alterations in the bioreactor. Hence, the understanding of cell morphology became an important key to enhancing and optimizing productivity [8].

With the recent development of new analytical procedures based on image analysis $[8,12,13,14]$ for characterization of morphological changes, it is nowadays possible to relate the environmental conditions to growth kinetics. In this connection, this work deals with $Y$. lipolytica morphology alterations determined under conditions of thermal and oxidative stress.

\section{2}

\section{Materials and methods}

\section{1}

\section{Experimental conditions}

A wild type strain of Yarrowia lipolytica (IMUFRJ 50682) was selected from an estuary in the vicinity of Rio de 

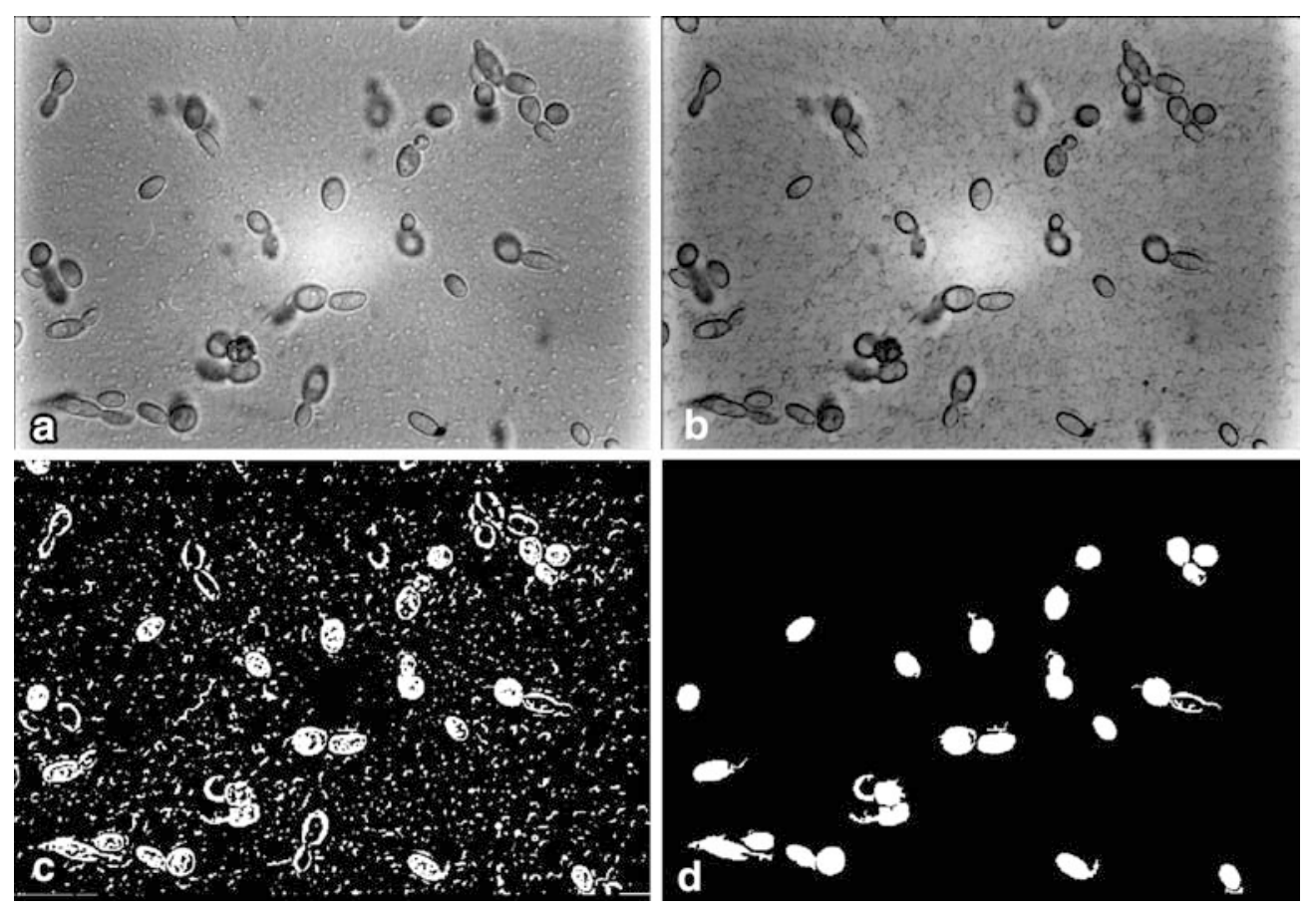

Fig. 1a-d. Some steps in the image treatment procedure

Janeiro, Brazil [16]. Cells were cultivated in YPD medium (glucose $2 \%$, peptone $0.64 \%$, yeast extract $1 \%$ ) at $29^{\circ} \mathrm{C}$ in a rotary shaker $(160 \mathrm{rpm})$.

Thermal stress experiments were carried out, employing a temperature shift from 29 to $37^{\circ} \mathrm{C}$ during $1 \mathrm{~h}$. For oxidative studies, $\mathrm{H}_{2} \mathrm{O}_{2}$ was added to reach final concentrations ranging from 0 to $20 \mathrm{mM}$. Both stress conditions were applied at the exponential growth phase. Control experiments were conducted in parallel to stress experiments for comparison.

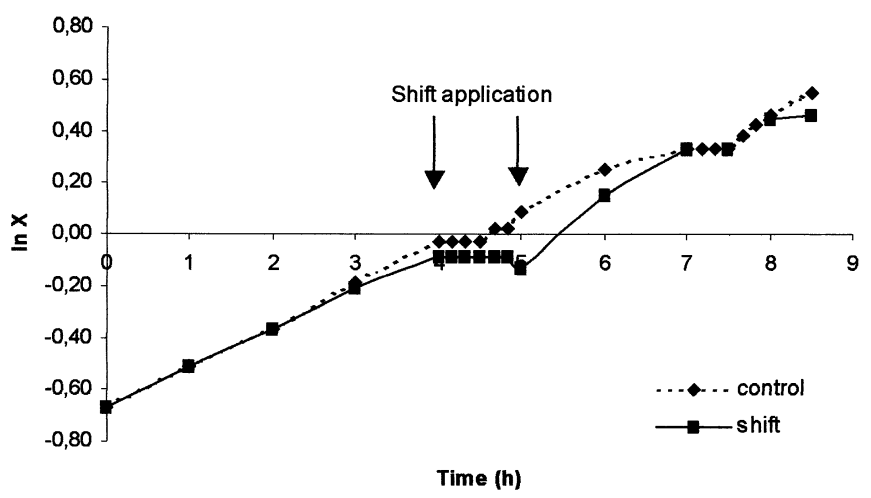

Fig. 2. Kinetic growth under control conditions and thermal stress applied in the exponential phase

Table 1. Kinetic parameters for Y. lipolytica growth under thermal stress and control conditions

\begin{tabular}{lcl}
\hline & Control & Thermal stress \\
\hline$\mu_{\max }\left(\mathrm{h}^{-1}\right)$ & $0.30 \pm 0.07$ & $0.31 \pm 0.14$ \\
$\mathrm{~K}_{\mathrm{s}}(\mathrm{g} / \mathrm{L})$ & $19.98 \pm 0.17$ & $14.37 \pm 0.28$ \\
$Y_{X / S}(\mathrm{~g}$ cell/g glucose $)$ & $0.36 \pm 0.01$ & $0.76 \pm 0.00$ \\
\hline
\end{tabular}

Cell concentration was followed by optical density measurements at $570 \mathrm{~nm}$, and those values were converted to $\mathrm{mg}$ d.w./mL using a factor previously determined.

\section{2}

\section{Image analysis procedure}

Cell morphology was observed using an Axiolab Zeiss optical microscope with $1,000 \times$ magnification along the batch growth, in both control and stress conditions. Traditional tools generally used for image enhancing were employed. The RGB image was decomposed into its respective channels, and the green channel was employed in the image treatment steps (Fig. 1a). Afterwards, a grayscale intensity image was created and a combination of bottom and top hat filtering was used to enhance image contrast (Fig. 1b). A binarization step was performed (Fig. 1c) followed by the elimination of border structures and a hole-fill procedure was carried out. Application of

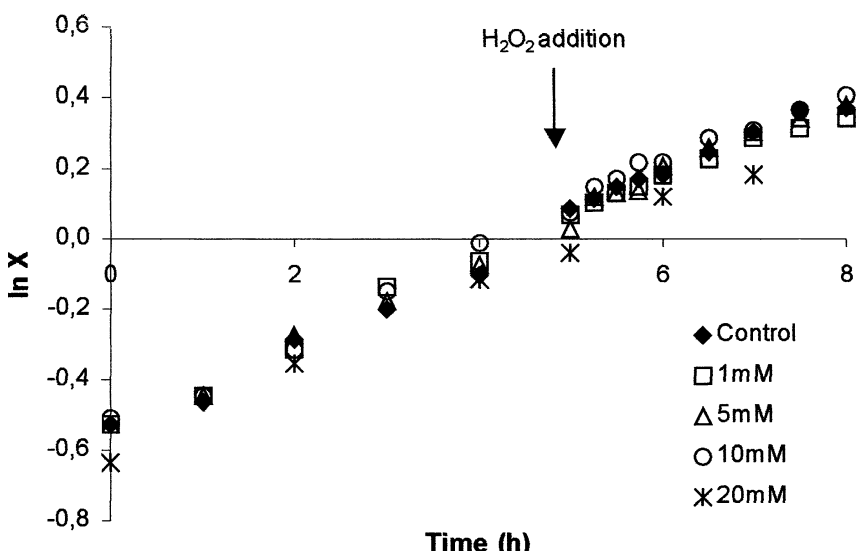

Fig. 3. Kinetic growth under control conditions and oxidative stress 

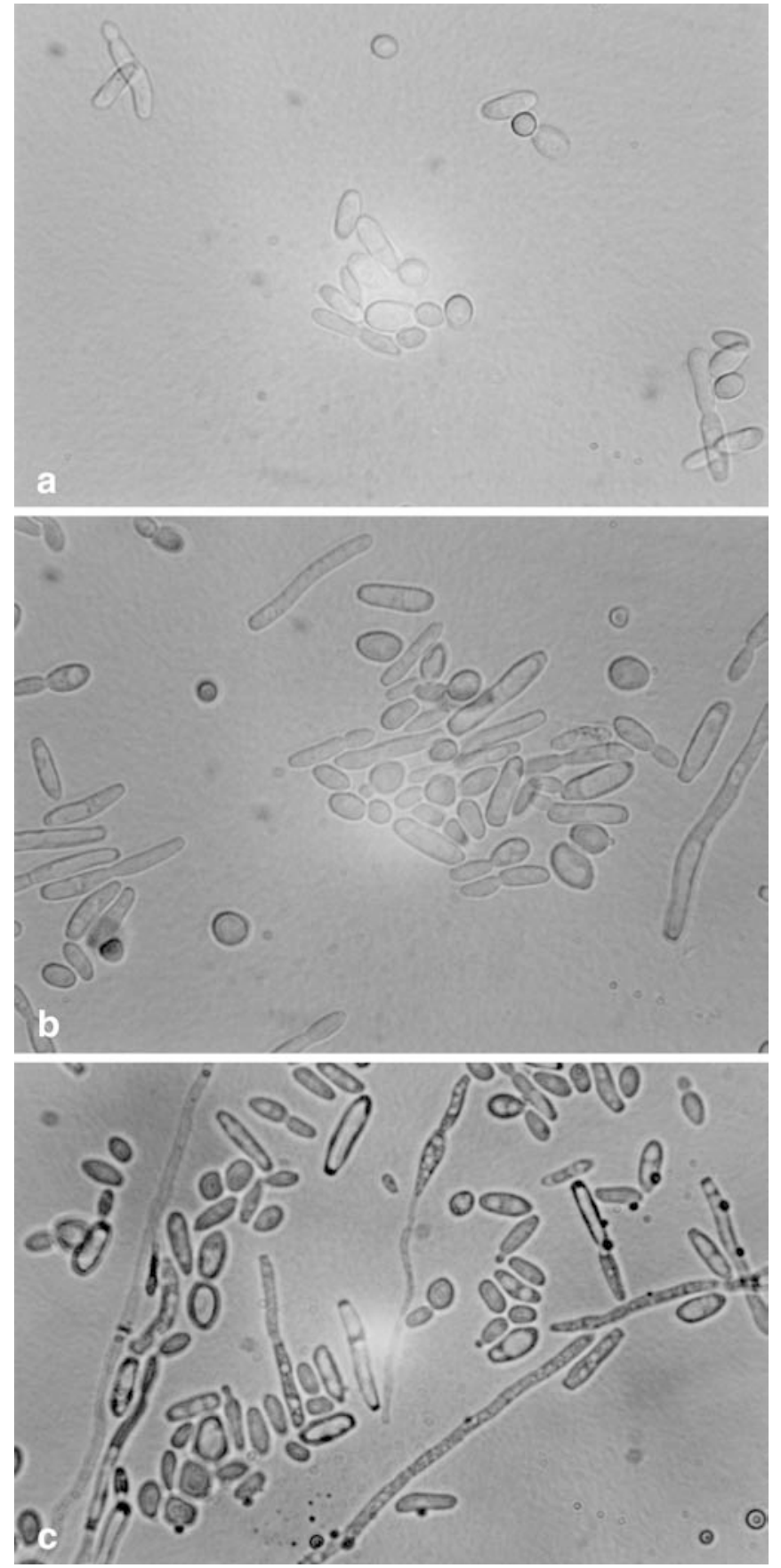

Fig. 4a-c. Kinetic hyphae formation during thermal stress application: a control system; $\mathbf{b}$ after $1 \mathrm{~h}$ of shift application; $\mathrm{c}$ after $2 \mathrm{~h}$ of shift application

morphological operations, such as erosion (to remove small debris) and reconstruction, gave the final image (Fig. 1d). This image treatment was performed in Matlab v.6.1 (The Mathworks Inc., Natick) platform and was fully automated, running under batch mode.

In order to extract the cells' individual properties, their characteristics were determined using image analysis of the labeled objects: Area is the area of the projected surface of the object on the plane of vision; hyphal length and hyphal width were determined as the maximum Feret diameter $\left(F_{\text {Max }}\right)$ and minimum Feret diameter $\left(F_{\text {Min }}\right)$,
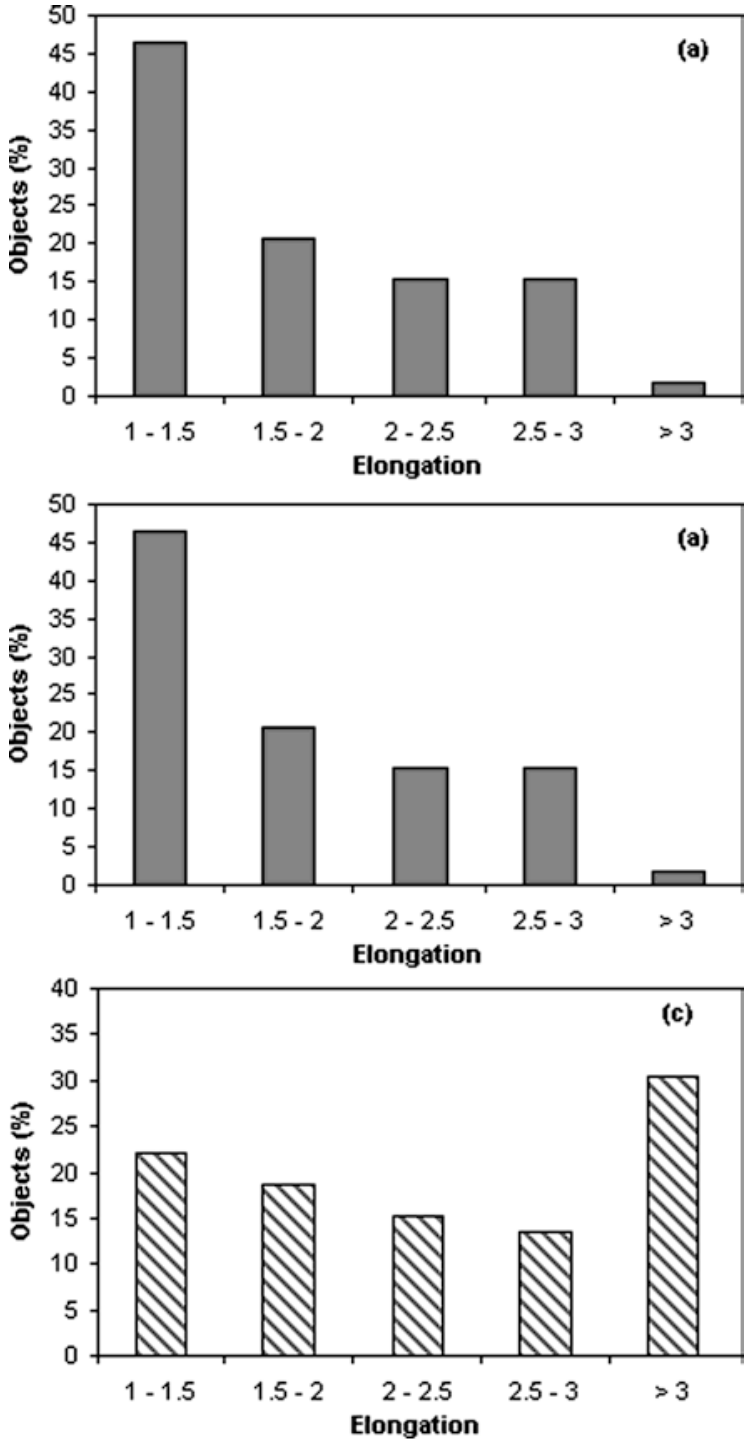

Fig. 5a, b. Elongation factor distribution for: a control system; b thermal stress conditions; $\mathbf{c}$ oxidative conditions

respectively. The Feret diameter is given by the distance between two parallel tangents in any given direction [17]. Elongation is given by the ratio between hyphal length and hyphal width:

Elongation $=\frac{F_{\mathrm{Max}}}{F_{\mathrm{Min}}}$

3

\section{Results and discussion}

\section{1}

\section{Kinetic data in control and stress conditions}

The thermal stress applied in the exponential growth phase leads to a stop cell growth during the application of the temperature shift, as shown in Fig. 2.

This period of growth stagnation may occur due to a rearrangement in the cell metabolism in new environmental conditions. As a consequence of these new 

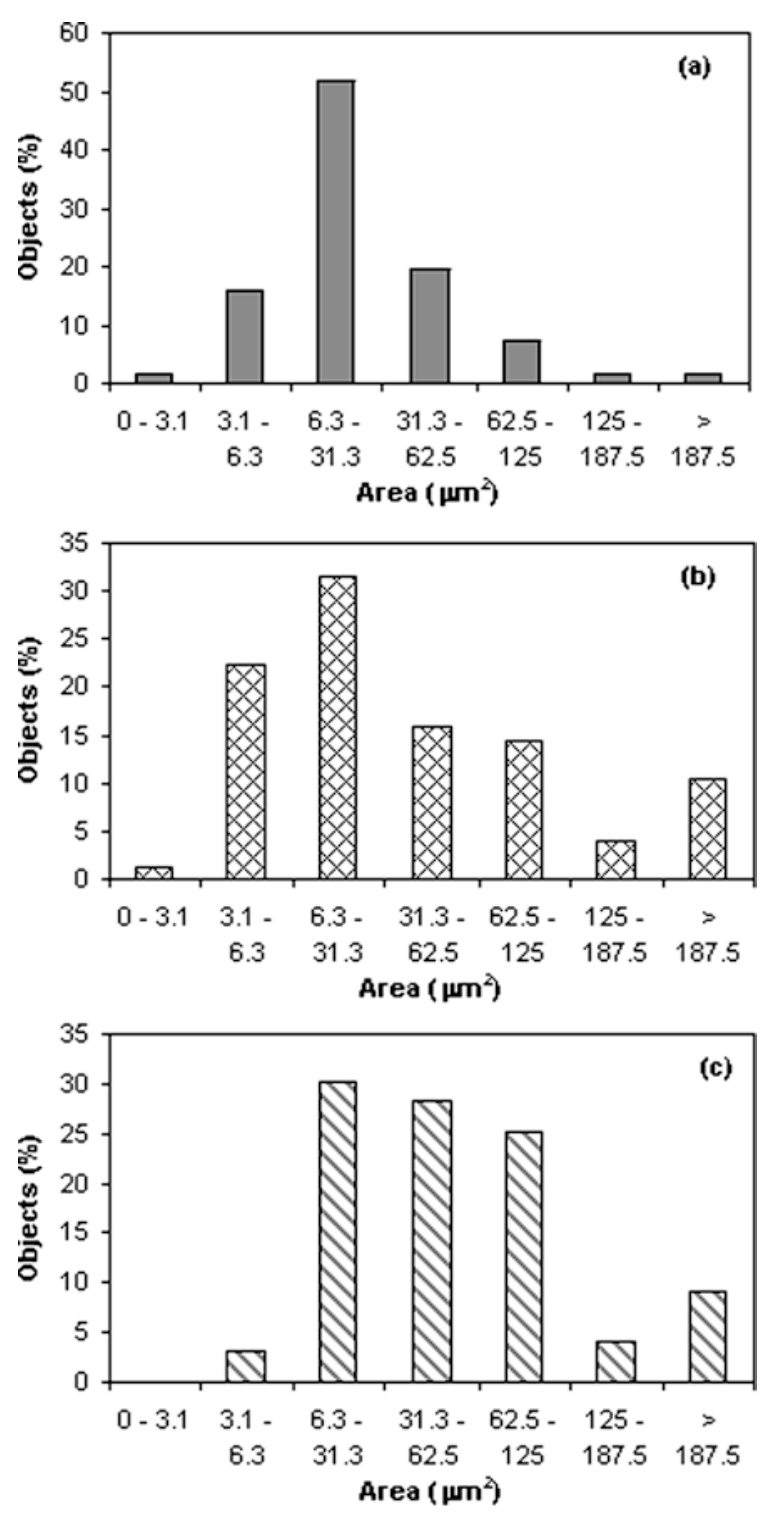

Fig. 6a-c. Size distribution for: a control system; b thermal stress conditions; c oxidative conditions

conditions, changes in cell yield with respect to carbon source $\left(\mathrm{Y}_{\mathrm{X} / \mathrm{S}}\right)$ were achieved. This fact can be observed by comparing it with the control condition. However, no significant modification of the maximum growth velocity $\left(\mu_{\max }\right)$ was observed (Table 1$)$.

For oxidative stress, the concentrations of $\mathrm{H}_{2} \mathrm{O}_{2}$ between 0.1 and $20 \mathrm{mM}$ do not present any considerable effect in the growth progress compared with the control cells, as shown in Fig. 3. A $10 \mathrm{mM}$ solution of $\mathrm{H}_{2} \mathrm{O}_{2}$ was used in dimorphism studies, according to Kim et al. [17].

\section{2}

\section{Dimorphism induction under stress conditions}

Cell exposure to both thermal and oxidative stress conditions leads to an increase in the capacity of Y. lipolytica to form hyphae, as denoted by a morphological kinetic description in Fig. $4 a-c$.

Quantitative results were obtained with the aid of image analysis. Figure $5 \mathrm{a}-\mathrm{c}$ shows a distribution based on the
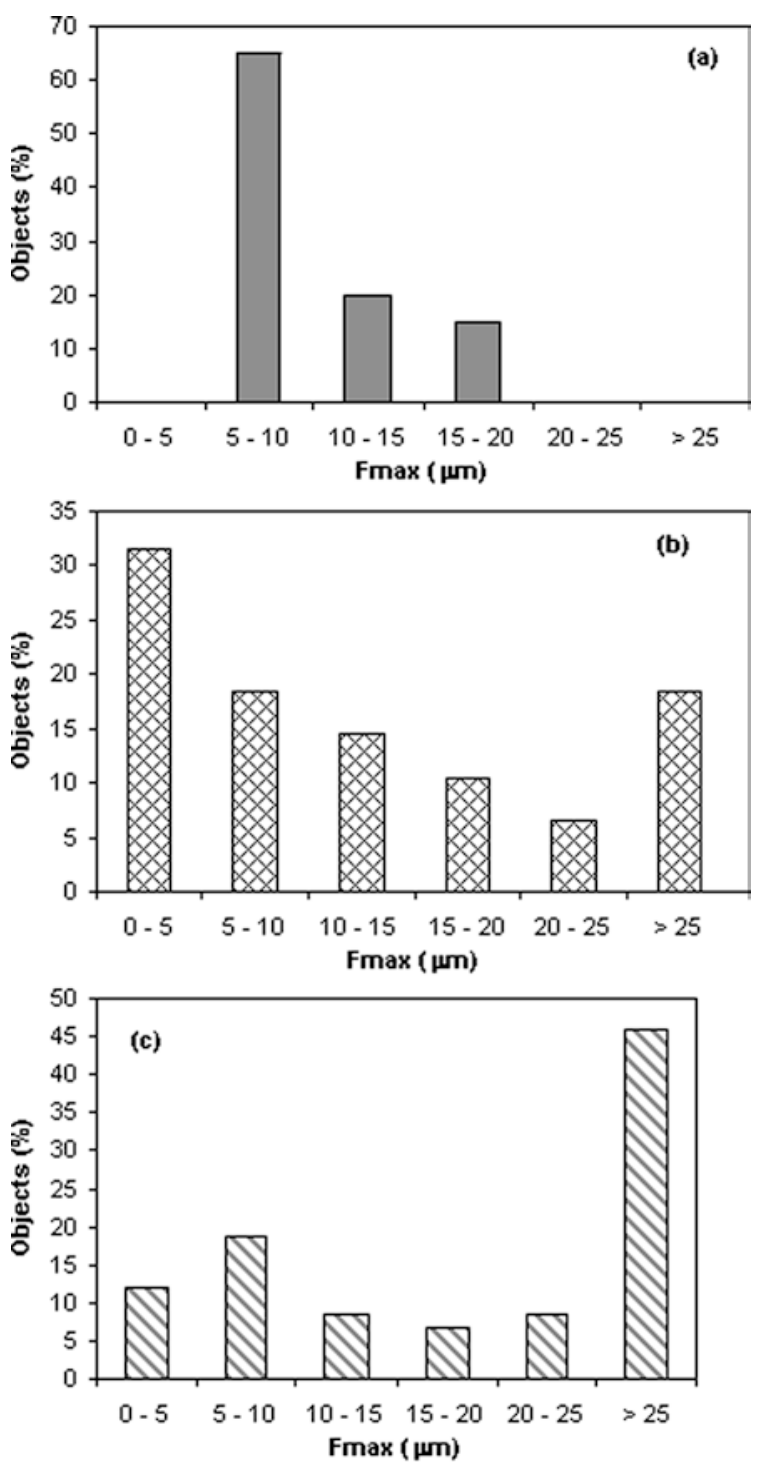

Fig. 7a-c. Total hyphal length determined for: a control system; b thermal stress conditions; c oxidative conditions

elongation factor $\left(\mathrm{F}_{\max } / \mathrm{F}_{\min }\right)$ for control, thermal and oxidative stress, respectively. This figure shows the presence of intermediate morphological forms in conjunction with hyphae and unicellular ones, as previously observed for other yeast systems $[8,14]$. Also, these results demonstrate an increase in the elongation factor of $25 \%$ for thermal and oxidative stresses, indicating that both conditions gave similar results with respect to hyphae formation intensity. Thus, it is possible to conclude that there is a relationship between the cell defense system and morphological changes.

The typical size distributions for all systems studied can be observed in Fig. 6a-c. For the control, the usual Gaussian size distribution was obtained. This characteristic behavior is no longer observed in stress systems, leading to a representative percentage of cells with high area values. Unfortunately, this parameter may not be adequate for dimorphism studies, since the cells shifted to a different morphological structure. 
As denoted by O'Shea and Walsh [14], the complexity and diversity of biological systems require different parameters for morphological characterization with respect to cell type (bacteria, fungi, mammalian, or plant). For the filamentous types, the typically measured and calculated parameters include main hyphae length, total hyphal length, and branching frequency, among others. As observed in Fig. 4a-c, Yarrowia lipolytica forms long and straight hyphae without any branches, permitting a study of total hyphal length through $F_{\max }$, as described in Fig. $7 \mathrm{a}-\mathrm{c}$. Although it is possible to attest an increase in hyphae characteristic length in both stress cases, an oxidative condition enabledhigher values to be achieved compared with thermal cases.

\section{4}

\section{Conclusions}

Thermal stress conditions applied to Y. lipolytica exponential growth lead to changes in cell yield, although $\mu_{\max }$ remains similar to that of the control. No significant difference was observed in the growth curve for oxidative stress conditions up to $20 \mathrm{mM}$. Dimorphism was observed and characterized by a net increase of around $25 \%$ in elongation factor. Both systems present an increase in total hyphal length.

\section{References}

1. Szabo R (2001) Genetic analysis of cell dimorphism in Yarrowia lipolytica. www.url:http://kovaclab.czweb.org/rsproj.htm

2. Hurtado CAR, Rachubinsk RA (1999) J Bacteriol 181: 3051-3057

3. Kron SJ (1997) Trends Microbiol 5:450-454

4. Cruz JM, Domínguez JM, Domínguez H, Parajó JC (2000) Biotechnol Lett 22:605-610

5. Szabo R (2001) Mol Genet Genom 265:172-179

6. Herrero AB, Lopez MC, Fernandez-Lago L, et al (1999) Microbiology 145:2727-2737

7. Barth G, Gaillardin C (1997) FEMS Microbiol Rev 19:219-237

8. O'Shea DG, Walsh PK (2000) Appl Microbiol Biotechnol 53:316322

9. Gancedo JM (2001) FEMS Microbiol Rev 25:107-123

10. Hurtado CAR, Beckerich JM, Gaillardin C, et al (2000) J Bacteriol 182:2376-2386

11. McCarthy AA, O’Shea DG, Murray NT, Walsh PK, Foley G (1998) Biotechnol Progr 14:279-285

12. Nielsen J (1996) Trends Biotechnol 14:438-443

13. Pons MN, Vivier H (1998) Morphometry of yeast. In Wilkinson MHF, Schut F. (ed) Digital image analysis of microbes: imaging, morphometry, fluorometry and motility techniques and applications. John Wiley, Chichester, pp 199-224

14. O'Shea DG, Walsh PK (1996) Biotechnol Bioeng 51:679-690

15. Haegler, AN, Mendonça-Haegler, LC (1981) Appl Environ Microbiol 41:173-178

16. Russ JC (1995) The image processing handbook. CRC Press, Boca Raton

17. Kim J, Cheon AC, Park S, et al (2000) FEMS Microbiol Lett 190:912 